\title{
CLUSTERS INDUSTRIAIS: UMA EXPERIÊNCIA NO BRASIL MERIDIONAL
}

\author{
Hoyêdo Nunes Lins *
}

\section{INTRODUÇÃO}

No período recente, ganhou terreno uma linha de análise sobre desempenho industrial que prioriza a observação dos ambientes produtivos e socioinstitucionais onde as firmas se localizam. Disseminada em termos internacionais, essa abordagem foca as concentrações geográficas de empresas setorialmente especializadas - ou clusters de atividades -, atribuindo importância fundamental às relações interfirmas e com instituições e realçando aspectos "endógenos", por assim dizer, do desenvolvimento local-regional. Estudos sobre clusters parecem ganhar espaço também no Brasil, conforme ilustram diferentes trabalhos sobre sistemas produtivos locais situados principalmente na região sul do país.

Inspirado no avanço do referido eixo de investigação, este artigo discorre sobre um cluster têxtil-vestuarista localizado no Médio Vale do Itajaí, em Santa Catarina, objetivando, basicamente, caracterizar o respectivo meio produtivo e socioinstitucional. O suporte empírico é um conjunto de informações obtidas mediante entrevistas em 22 empresas, a maioria de pequeno e médio porte (PMEs), de Blumenau e Brusque, áreas que "formam, englobadamente, um grande conjunto têxtil" (SINGER, 1977, p. 135). Efetuadas no âmbito de investigação mais ampla, ${ }^{1}$ as entrevistas procuraram captar a visão das empresas sobre a importância dos atributos locais para o desempenho industrial e a competitividade, seja em nível de firma, seja em escala de "sistema".

* Professor Doutor, Titular, do Depto. de Ciências Econômicas da Universidade Federal de Santa Catarina, com participação no Programa de Mestrado em Economia Industrial.hnlins@cse.ufsc.br 
A primeira parte do texto sistematiza algumas questões da problemática geral dos clusters industriais, o que é efetuado a partir da referência a um tipo particular de cluster: o "distrito industrial". Em seguida, abordam-se aspectos da evolução histórica da área têxtil-vestuarista estudada. A terceira seção caracteriza o sistema local (relativo ao Médio Vale do Itajaí) na perspectiva da problemática geral dos clusters: com apoio na pesquisa de campo, focalizam-se as características da mão-de-obra, a herança sociocultural, o tecido institucional e o problema da cooperação entre empresas. Após uma apreciação sobre aspectos positivos e carências, propugna-se, nas considerações finais, a definição de políticas de apoio e promoção às empresas têxteis-vestuaristas regionais, as PMEs em primeiro lugar.

\section{A PROBLEMÁTICA DOS CLUSTERS INDUSTRIAIS}

O desenvolvimento das análises sobre dinâmica industrial em termos de clusters parece ter sido largamente inspirado na experiência européia dos "distritos industriais", em especial na versão italiana, que se tornou paradigmática. O que são "distritos industriais"? Trata-se, antes de tudo, de clusters de atividades. Entretanto, suas características transcendem o aspecto da simples concentração geográfico-setorial. Estudos como os de Beccatini (1992a, b), Rabellotti (1995) e Schmitz (1995a, b) permitem uma visão sintética dos seus elementos constituintes:

- concentração espacial de firmas, principalmente PMEs, setorialmente especializadas;

- relações interfirmas a montante e a jusante (fornecedoresclientes), quer mercantis, quer não mercantis, no interior do cluster;

- desintegração vertical da produção em nível de firma, com especialização das empresas em fases do processo produtivo;

- oferta local de serviços especializados de apoio às atividades produtivas e também voltados à comercialização em mercados distantes, inclusive no exterior;

- competição cooperativa entre os agentes econômicos;

1 Pesquisa sobre internacionalização e competitividade de PMEs do complexo têxtil-vestuário de Santa Catarina, financiada pelo CNPq e coordenada pelo autor. 
- identidade sociocultural, relacionada a um passado comum, que contribui para galvanizar as relações entre os atores sociais, cuja atuação tende a ser norteada por um código de comportamento via de regra implícito;

- rede de instituições públicas e privadas locais que sustentam as ações dos agentes no interior do "distrito", tendo em vista que representam/envolvem a organização de autoajuda.

Os "distritos industriais" europeus apresentam combinações de setores de alta tecnologia e tradicionais, com empresas que tanto fazem pesquisa e desenvolvimento $(\mathrm{P} \& \mathrm{D})$ quanto operam em subcontratação. A constelação de firmas é bastante segmentada, pois as diferentes fases dos processos produtivos são distribuídas entre diversas unidades especializadas na execução de uma ou algumas delas. Por outro lado, embora os "distritos" sejam geralmente monoprodutores (na experiência italiana observam-se plásticos em Verona e têxtil em Prato, por exemplo), pode haver estímulo à diversificação tão $\operatorname{logo}$ o sistema local torne-se suficientemente forte. Sua organização e seu funcionamento ganham melhor compreensão quando se lhes relacionam os aspectos histórico-culturais referentes à gênese e trajetória. Muitos desses conjuntos produtivos "foram criados sobre a base de sociedades locais específicas (...) cujos recursos sociais serviram de fundamento e continuam a assegurar a regulação do novo sistema produtivo" (RITAINE, 1989, p. 161).

Digno de nota é o fato de que, pelo menos na Itália, o próprio "retardo" industrial das sociedades locais envolvidas favoreceu o desenvolvimento observado, pois garantiu "recursos" como: uma organização familiar preservada, que permitiu manter e dinamizar as unidades produtivas de pequeno porte; a ética do trabalho, de origem artesanal, que serviu de substrato ao processo; e o controle social, baseado no conhecimento mútuo e profundo. Portanto, aludir aos "distritos industriais" implica ir além de questões estritamente econômicas. Tais "distritos" são efetivas unidades socioterritoriais, simultaneamente "campo da concorrência acirrada e da solidariedade, do costume e das instituições informais" (BECCATINI, 1992b, p. 159), sustentadas por combinações de relações de mercado e laços de família, de concorrência e solidariedade, e permeadas dos princípios de confiança e reciprocidade como pilares da organização local.

No interior desses sistemas locais, o desempenho individual das firmas estaria relacionado à "eficiência coletiva", isto é, à associação entre 
externalidades locais e ação conjunta e deliberada dos agentes visando a encontrar soluções para problemas comuns em escala de coletividade de fabricantes. ${ }^{2}$ Está-se referindo aos benefícios vinculados à existência de:

- economias externas estáticas, fruto da redução de custos proporcionada pela localização específica;

- economias externas dinâmicas, derivadas de processos (espontâneos e socialmente difundidos) envolvendo educação, treinamento e acúmulo de conhecimentos;

- economias de proximidade, envolvendo menores custos de transação e outros, devido à maior circulação de informações e aos contatos face-a-face;

- elementos de sinergia, favorecendo e fortalecendo a capacidade de inovação local mediante imitações; interações diversas, parcerias público-privadas envolvendo a oferta de serviços e infra-estrutura, e cooperação fornecedor-cliente, entre outros elementos, constituem vetores de sinergia.

Essas características permitem aos "distritos" abrigar processos de produção flexíveis e especializados. Em boa medida, a referida flexibilidade baseia-se em relações especiais no mercado de trabalho local, com destaque para a utilização intensiva de trabalhadores domésticos e a disponibilidade de mão-de-obra para trabalho até em horários extras. Adaptações rápidas no uso da força de trabalho tornam-se possíveis e, desse modo, pode-se reagir com velocidade às mudanças no mercado. A especialização, de sua parte, resulta de divisão do trabalho nos processos de produção em que, ao nível de cada firma e comparativamente à produção verticalmente integrada, tornase possível explorar mais eficientemente as economias de escala, com aumento da capacidade de inovação.

2 O conceito de "eficiência coletiva" tenta captar o aspecto essencial do desempenho econômico no interior dos clusters: a articulação de externalidades, vistas como subproduto incidental, algo involuntário, de situações ou processos, com ações deliberadas. Conforme Schmitz (1995b), “...a noção de economias externas veio a ser associada com ganhos (ou perdas) resultantes da operação de firmas conectadas através de um mercado anônimo e cujo comportamento é determinado meramente por sinais de preço e custo. Isso tende a esconder traços essenciais das firmas num cluster bem desenvolvido: nomeadamente, os limites entre firmas são geralmente flexíveis, as relações entre elas são caracterizadas tanto por competição como por cooperação, e confiança e reciprocidade são importantes para entender a densidade das transações e a incidência da ação conjunta no cluster" (p. 536). A posição deste autor aparece também em outros textos: por exemplo Schmitz (1992, 1997). 
A noção de "distrito industrial" remonta às análises de Alfred Marshall sobre localização de atividades industriais, realizadas no final do século passado. Em seus Princípios de Economia, ${ }^{3}$ o autor ressaltava o quanto era importante para a indústria localizar-se em determinados lugares, devido aos benefícios que os entornos representavam. O elemento chave do enfoque eram as vantagens associadas às economias externas.

Entretanto, desenvolvimentos recentes nas pesquisas sobre dinâmicas industriais agregam elementos novos ao debate sobre as aglomerações setorialmente especializadas. A concentração geográfica e setorial de firmas - o cluster - figura como elemento básico do arranjo sócioprodutivo relacionado à forma "distrito industrial", mas a configuração espacial correspondente (a concentração geográfica) não proporciona, forçosa e automaticamente, os principais ganhos para o sistema produtivo local. Os ganhos mais importantes resultam da articulação local entre as economias externas, ligadas à própria existência do cluster, e a ação conjunta, deliberada, desencadeada no âmbito da aglomeração produtiva com vistas ao alcance de certos objetivos em nível de coletividade de produtores. ${ }^{4} \mathrm{~A}$ concentração geográfica e setorial favorece e até induz a ação conjunta, mas não é "sinônimo" desta. Pode-se mesmo considerar que o futuro de um cluster é tanto mais promissor quanto mais intensos forem os vínculos de cooperação existentes entre os agentes que o integram, especialmente entre as empresas.

Em outras palavras, o cluster não se confunde necessariamente com o "distrito industrial", modalidade de arranjo sócio-produtivo impregnada de cooperação. A "forma cluster" configura condição necessária ao desempenho positivo do sistema local, um elemento facilitador das interrelações, mas não garante a performance. De acordo com Schmitz (1995b), com efeito, "é importante lembrar que, enquanto um distrito industrial é sempre um cluster, o contrário não é sempre o caso" (p. 536).

A percepção de que a base do modelo "distrito industrial" reside na articulação entre economias externas e ação conjunta, capturada pelo conceito de "eficiência coletiva", permite ir além da visão marshalliana sobre desempenho industrial localizado. Marshall atribui as vantagens da concentração geográfica e setorial à existência de economias externas, porém é sobretudo a ação conjunta e deliberada dos agentes locais (através de vínculos horizontais, verticais e multilaterais) que configura esteio fundamental do desempenho. Nadvi (1997) sugere considerar as economias

3 Cf. MARSHALL (1979), cap. X, sobretudo p. 225-226.

4 Cf., por exemplo, SCHMITZ (1997). 
externas como elemento "passivo" da "eficiência coletiva", e a ação conjunta, como o seu elemento "ativo". Desde logo, identificar a natureza dos vínculos interfirmas, das formas de ação conjunta, no âmbito dos processos de cluster reveste-se de evidente importância. Cabe frisar que a ênfase nos vínculos não significa postular que clusters sejam ilhas de solidariedade. A competição é acirrada, mas isso não exclui a ação conjunta, a cooperação.

Estudos recentes sugerem que a "forma distrito" favorece o desempenho das empresas, principalmente das PMEs, em contextos de incertezas e desafios, como os relacionados à liberalização comercial e à globalização econômica. ${ }^{5}$ Até mesmo para países menos industrializados considera-se que as conexões e os espaços de cooperação podem proporcionar resultados que transcendem a mera sobrevivência das empresas e a geração de empregos apenas confinada às relações informais de trabalho. Assim, não surpreende que as novas propostas de apoio às PMEs contemplem as relações interfirmas, mais do que as dificuldades localizadas no interior das empresas ou incrustadas no ambiente macroeconômico. $\mathrm{Na}$ base encontra-se a convicção de que "o sucesso industrial não pode ser apreendido pela análise das firmas individuais. Sua força reside no clustering e na competição cooperativa, que permitem ganhos de eficiência e flexibilidade, os quais podem ser raramente alcançados por produtores individuais" (SCHMITZ; MUSYCK, 1994, p. 890, ênfase no original).

Essas considerações sobre dinâmica industrial territorializada, centradas nas noções de cluster e "distrito industrial", inspirarão a abordagem sobre a área de produção têxtil-vestuarista referente ao Médio Vale do Itajaí.

\section{MÉDIO VALE DO ITAJAÍ: UM CLUSTER TÊXTIL- VESTUARISTA CATARINENSE}

O Médio Vale do Itajaí é a principal área de produção têxtilvestuarista de Santa Catarina e uma das mais importantes do Brasil. Em meados dos anos 80, Blumenau, a principal cidade da região, concentrava $51 \%$ e $46 \%$ da produção catarinense de artigos têxteis e de vestuário, ${ }^{6}$ respectivamente, e Santa Catarina ocupava o terceiro lugar no ranking dos estados brasileiros quer no ramo têxtil, quer no de vestuário, calçados e

5 Consultar NADVI e SCHMITZ (1997).

6 As percentagens são apresentadas em CUNHA (1992). 
artefatos de tecidos, no que concerne ao valor da transformação industrial. ${ }^{7}$ Para a economia da região, a importância das indústrias em foco torna-se evidente quando se constata que a produção têxtil-vestuarista representa $2 / 3$ do total da indústria de Blumenau. ${ }^{8}$

Essas indústrias apresentam história irrevogavelmente vinculada ao processo de colonização protagonizado por imigrantes de origem germânica durante o século XIX. Os primeiros passos realmente importantes da trajetória setorial ocorreram entre 1880 e 1914, período em que foram criadas as primeiras unidades de produção, algumas das quais ainda em atividade nos dias atuais. Não parece equivocado considerar que essas atividades destacaram-se precocemente no Médio Vale do Itajaí devido à herança fabril e setorial de parte dos imigrantes. Na base do movimento migratório figuravam transformações em solo europeu que multiplicaram as dificuldades para numerosos mestres-artesãos, os quais, em diversos casos, viram-se compelidos a se transferir para territórios além-mar. Nos locais de destino em que as condições locais eram favoráveis, a tradição profissional prevaleceu e deu origem a diversas atividades produtivas. A história da Hering é uma boa ilustração: Hermann Hering, mestre em tecelagem de meias e luvas (assim como todos os membros masculinos de sua família durante várias gerações), fundou em 1880, somente dois anos após chegar em Blumenau, a fábrica de produtos de malha que daria partida à trajetória de uma das maiores firmas do ramo no país. ${ }^{9}$

Entre 1914 e o fim da Segunda Guerra Mundial, a indústria têxtil do Médio Vale do Itajaí cresceu e consolidou-se. O primeiro conflito permitiu a Blumenau ampliar seus espaços de comercialização em escala nacional, e já na década de 20 a economia da região mostrava-se relativamente integrada ao mercado brasileiro, principalmente através das vendas de camisas de "meia". "Tudo leva a crer que o período da Primeira Guerra (1914/1918) e a década seguinte constituem um período de transição, ao cabo do qual, um número apreciável de empresas de Blumenau não somente passa a abastecer o mercado nacional como vêem nele o alvo principal de sua atividade produtiva. Inicia-se deste modo o que denominamos de etapa da grande indústria..." (SINGER, 1977, p. 129, em itálico no original). Na segunda metade do século $\mathrm{XX}$ as grandes empresas do setor romperam os limites das vendas internas e passaram a marcar presença em mercados internacionais, inclusive

7 A posição catarinense na hierarquia brasileira de produção têxtil-vestuarista é mostrada em Santa Catarina em Dados (1996).

8 De acordo com dados para a década de 80, cf. CUNHA (1992).

9 Consultar HERING (1987) sobre a trajetória histórica da indústria têxtil no Vale do Itajaí. 
naqueles mais dinâmicos e seletivos, como os dos países mais industrializados. No movimento de internacionalização, houve empresas que, inclusive, instalaram unidades produtivas no exterior, como fez a Hering na Espanha.

Aspecto que merece realce é que nas últimas décadas a participação das atividades vestuaristas no conjunto da produção têxtil cresceu substancialmente em Santa Catarina. De fato, entre os censos industriais de 1960 e 1985, o gênero "têxtil" teve a sua participação no total da indústria de transformação catarinense reduzida de $15,1 \%$ para $11,5 \%$ e de $17,8 \%$ para $9 \%$, respectivamente, no que se refere ao valor da transformação industrial e ao pessoal ocupado, enquanto que a presença do gênero "vestuário, calçados e artefatos de tecidos" foi ampliada de 1,3\% para 13,2\% e de $1,7 \%$ para $17 \%$, na mesma ordem. Tal comportamento, de projeção rumo ao segmento vestuarista, significou tendência de proliferação de empresas menores, envolvidas não só em prestação de serviços de beneficiamento, mas também, e principalmente, na fabricação de malhas e artigos de vestuário.

No Médio Vale do Itajaí, a dinâmica de crescimento das PMEs com presença nessas atividades apresentou semelhança com o que ocorreu em outras regiões, como na de Joinville (nordeste catarinense), onde exfuncionários de grandes empresas instalaram-se na condição de fabricantes e prestadores de serviços. Porém, enquanto nessa área tal processo teria ganho força principalmente desde os anos 80 , no bojo da crise experimentada por várias empresas locais de maior porte (que encerraram ou reduziram atividades), no Médio Vale do Itajaí a trajetória parece mais longa, coerente com o caminho trilhado pela região enquanto destacado espaço de produção têxtil-vestuarista em escala de Santa Catarina e de país. Só mais recentemente, devido ao acirramento da concorrência, por conta da abertura comercial do Brasil, e às conseqüentes iniciativas de reestruturação produtiva e organizacional, o desemprego adquiriu dimensão importante como substrato da proliferação de distintos negócios de menor porte no Médio Vale do Itajaí, muitos deles (certamente a maioria) caracterizados pela mais completa informalidade.

Uma trajetória setorial como essa não deixaria de resultar em rico ambiente produtivo e socioinstitucional relacionado à produção têxtilvestuarista. Em que medida os atributos locais realmente favorecem o desempenho do coletivo de fabricantes? 


\section{LUZES E SOMBRAS DO CLUSTER TÊXTIL-VESTUARISTA CATARINENSE}

A partir das entrevistas mencionadas na introdução, realizadas em 22 empresas com presença em vários pontos da cadeia produtiva têxtilvestuarista e diferentemente caracterizadas (tabela 1), abordam-se aspectos de Blumenau e Brusque relacionados com mão-de-obra, herança sociocultural, instituições e vínculos de cooperação. Trata-se de questões geralmente salientadas em estudos sobre clusters industriais, e sua observação fornece uma idéia sobre os atributos do Médio Vale do Itajaí no que concerne às atividades em foco.

Tabela 1 - CARACTERÍSTICAS DO PAINEL DE EMPRESAS ENTREVISTADAS

\begin{tabular}{l|c|l|c}
\hline \multicolumn{1}{c|}{ Pessoal ocupado } & $\mathbf{N}^{\mathbf{0}}$ de empresas & \multicolumn{1}{|c}{ Faturamento (US\$ mil) } & $\mathbf{N}^{\mathbf{0}}$ de empresas \\
\hline Até 50 & 6 & Até 3.000 & 11 \\
\hline Mais de 50 até 100 & 4 & Mais de 3.000 até 6.000 & 4 \\
\hline Mais de 100 até 250 & 6 & Mais de 6.000 até 15.000 & 2 \\
\hline Mais de 250 até 500 & 4 & Mais de 15.000 até 25.000 & 3 \\
\hline Mais de 500 & 2 & Mais de 25.000 & 2 \\
\hline Total & 22 & Total & 22 \\
\hline
\end{tabular}

FONTE: Pesquisa direta nas empresas.

\section{Características da mão-de-obra e herança sociocultural}

Para várias empresas, as características do mercado de trabalho representam importante vantagem locacional do Médio Vale do Itajaí (tabela 2). A secular trajetória das indústrias em foco significou o envolvimento de várias gerações de trabalhadores na produção têxtil-vestuarista, representando a formação de uma verdadeira "cultura" setorial na região, o que quer dizer mão-de-obra familiarizada com as práticas correspondentes e qualificação profissional não negligenciável. É verdade que os níveis salariais na produção têxtil-vestuarista do Médio Vale do Itajaí situam-se entre os mais elevados de Santa Catarina, mas as empresas geralmente enalteceram as condições do mercado de trabalho local, quer pelo nível de conhecimento e habilidade dos trabalhadores, quer pelo que foi reconhecido como uma certa inclinação à conduta cooperativa de parte da maioria. $\mathrm{O}$ "clima social positivo" foi assinalado por diferentes fabricantes como importante atributo regional, especialmente em Brusque.

Entretanto, não há consenso entre as empresas sobre esse assunto. Um médio fabricante de Blumenau lamentou ter que utilizar 
trabalhadores "da pior espécie, que não cooperam e só pensam no salário, pois mudou o perfil da mão-de-obra", aludindo às transformações observadas em cidades importantes de todo o Vale do Itajaí e do nordeste de Santa Catarina. No Médio Vale, essas mudanças têm sido observadas principalmente em Blumenau, onde, ao que parece, vem crescendo a participação de migrantes nas últimas décadas, com origens tanto em municípios mais ou menos próximos quanto em áreas do planalto catarinense e de outros estados. Os fluxos são geralmente caracterizados por níveis de escolaridade reduzidos e escasso preparo profissional, compostos por candidatos certos à ampliação da oferta de mão-de-obra de baixa remuneração.

Em Blumenau, a mistura de capacidade de mobilização sindical com salários altos estimulava, entre algumas empresas, o interesse na transferência das atividades para outras localizações, em sintonia com o que parece configurar uma certa tendência no Médio Vale do Itajaí. Entretanto, a tentativa de redistribuir as atividades em locais de baixos salários não configura novidade na região. Já em meados dos anos 80 caracterizava-se a organização das indústrias têxteis e vestuaristas na área indicando a existência de "inúmeras sedes municipais ou proximidades com um ou dois estabelecimentos de grande porte, freqüentemente filiais-integradas como as seções de costura das grandes malharias (...) e numerosos estabelecimentos espalhados pela zona rural..." (MAMIGONIAN, 1986, p. 105). O que parece novo é que agora os espaços de transferência referem-se a regiões distantes, como o nordeste brasileiro, e entre as motivações para o deslocamento observam-se as fortes pressões concorrenciais relacionadas à abertura comercial do país.

As opiniões das firmas de Brusque sobre as características do mercado de trabalho local foram geralmente homogêneas. Houve empresas que atribuíram a manutenção do caráter "tranqüilo" das relações capitaltrabalho, em grande parte, ao vertiginoso crescimento das demissões desde o Plano Real. Entretanto, talvez a avaliação sobre a natureza do "diálogo social" tenha sido influenciada pelo fato de que, na trajetória das indústrias têxteis e vestuaristas da região, tem sido numeroso o contingente de lavradores-operários utilizados. É que a possibilidade de utilizar mão-deobra de origem rural representa vantagens para as empresas. Entre outras coisas, isso resulta da menor (se há alguma) organização operária desses contingentes de trabalhadores. Entretanto, pode-se considerar que o fato da reprodução da força de trabalho ocorrer parcialmente no âmbito da propriedade rural tende a favorecer salários comparativamente menores.

Para várias empresas pesquisadas, as características da mão-deobra regional guardam relação com a herança sociocultural do Médio Vale 
do Itajaí. Daí que tal vinculação aparece como elemento básico de consideração dessa herança como um fator de competitividade regional. Mas também em relação a esse assunto, perceberam-se diferenças de opinião entre firmas de Blumenau e Brusque. Algumas empresas blumenauenses avaliaram que a herança predominantemente germânica de boa parte da população nada significava como vetor de competitividade. Em um ou outro caso, argumentou-se que a região perdera muito das características relacionadas àqueles traços culturais, em decorrência de movimento migratório que, pelo menos no começo dos anos 90, significava a chegada de centenas de famílias por ano em Blumenau. Em Brusque, a visão de que a origem germânica constitui atributo favorável ao desempenho das firmas foi unânime. Para essas firmas, tal herança traduz-se em culto ao trabalho entre os membros da comunidade, com influência sobre o comportamento da mãode-obra e a conduta do empresariado.

Tabela 2 - PERCEPÇÃO DAS EMPRESAS SOBRE A IMPORTÂNCIA DE ASPECTOS LIGADOS AO MERCADO DE TRABALHO LOCAL

\begin{tabular}{l|c|c|c|c}
\hline \multicolumn{1}{c|}{ Aspectos observados } & $\begin{array}{c}\text { Positivo para a } \\
\text { competitividade }\end{array}$ & $\begin{array}{c}\text { Negativo para a } \\
\text { competitividade }\end{array}$ & $\begin{array}{c}\text { Sem influênc. na } \\
\text { competitividade }\end{array}$ & $\begin{array}{c}\text { Total de } \\
\text { empresas }\end{array}$ \\
\hline Nível de qualificação dos trabalhadores & 20 & 2 & 0 & 22 \\
\hline Intensidade das ações sindicais & 5 & 5 & 12 & 22 \\
\hline Herança sociocultural da população & 17 & 0 & 5 & 22 \\
\hline
\end{tabular}

FONTE: Pesquisa direta nas empresas.

\section{Tecido institucional}

Igualmente realçados nas entrevistas foram os vínculos institucionais existentes na região (tabela 3). Tendo em vista a histórica representatividade da produção têxtil-vestuarista no Vale do Itajaí, a presença e a atuação de instituições ligadas às indústrias em foco são fatos que não surpreendem.

Tabela 3 - PERCEPÇÃO DAS EMPRESAS SOBRE ASPECTOS DA BASE INSTITUCIONAL

\begin{tabular}{l|c|c|c}
\hline \multicolumn{1}{c|}{ Aspectos observados } & Respostas positivas & Respostas negativas & Total \\
\hline Presença de vínculos institucionais importantes & 22 & 0 & 22 \\
\hline Presença marcante e decisiva do SENAI & 20 & 2 & 22 \\
\hline
\end{tabular}

FONTE: Pesquisa direta nas empresas.

A avaliação das estruturas de educação profissional (Senai, basicamente) foi geralmente positiva, pois, conforme sublinhado anteriormente, a qualificação da mão-de-obra configura atributo fundamental 
do Médio Vale do Itajaí na visão da maioria das empresas. É verdade que, para as firmas, qualificação queria normalmente dizer destreza e familiaridade com as tarefas relacionadas à produção têxtil-vestuarista, algo geralmente associado ao conhecimento "tácito", impregnado no próprio ambiente sócioprodutivo e cultural da região. Contudo, os Centros de Educação e Tecnologia do Senai, em Blumenau e em Brusque, oferecem um extenso e variado leque de atividades ligadas à educação profissional na área têxtilvestuarista. Essas atividades têm certamente contribuído para o aperfeiçoamento da mão-de-obra regional e, assim, figuram na origem da apreciação positiva das firmas sobre a base institucional voltada à educação profissional.

As referências aos laboratórios instalados nas dependências das agências locais do Senai devem ser especialmente consideradas. A agência de Blumenau abriga o Cepetex (Centro de Pesquisas e Desenvolvimento de Estudos Têxteis) e a FBET (Fundação Blumenauense de Estudos Têxteis), onde se realizam testes de resistência, alongamento e imperfeições em fios e fibras. A agência de Brusque também oferece serviços do gênero, voltados para testes químicos e físicos. A oferta de cursos, as possibilidades oferecidas para a utilização de equipamentos como $\mathrm{CAD},{ }^{10}$ a estrutura laboratorial e o suporte técnico e tecnológico figuram na base da avaliação das firmas sobre as atividades do Senai, consideradas essenciais pela esmagadora maioria dos entrevistados. Cabe destacar ainda a Universidade Regional de Blumenau, que parece atuar de forma articulada com os interesses do setor produtivo no que diz respeito à tecnologia e ao desenvolvimento.

As empresas geralmente desdenharam a atuação das Prefeituras Municipais: não mais do que uma empresa considerou positivo o desempenho da administração pública local. Já a avaliação das associações empresariais foi, em diversos casos, positiva. A Associação Comercial e Industrial de Blumenau (Acib), em particular, mereceu grande destaque, inclusive na comparação com outras instituições: um médio fabricante de artigos esportivos de Blumenau fez questão de frisar que "a Acib funciona", porém o sindicato patronal (Sintex) deixa a desejar.

A Acib e o Sintex representam as esferas básicas de articulação do empresariado têxtil-vestuarista de Blumenau, sob o controle da elite empresarial de ascendência germânica situada à frente das empresas

10 Um pequeno fabricante blumenauense de artigos infanto-juvenis informou que, mediante o pagamento de uma certa quantia por mês, tinha acesso ao sistema CAD instalado no Senai, onde se dirigia para fazer o encaixe e o molde em papel; depois, efetuava o corte na própria fábrica. 
tradicionais e de maior porte. Entretanto, as características de ambas as instituições não coincidem completamente. De acordo com Tomio (1995), há uma espécie de divisão de tarefas entre as duas: o Sintex priorizaria os interesses do grande empresariado, inclusive desestimulando a participação de empresas menores (via imposição de taxas de contribuição elevadas e exclusão deliberada de certos incentivos, por exemplo), ao passo que a Acib, mesmo conservando um caráter elitista e tradicional, atuaria de uma forma mais abrangente, na perspectiva da articulação do empresariado local de forma ampla. A Acib teria mesmo procurado aumentar a sua representatividade através do incentivo à participação de empresas menores. Sintoma disso é que a maioria dos seus associados é formada por micro e pequenos empresários, atraídos por serviços como assessoria jurídica e cursos de especialização profissional, por eventos como seminários e palestras e pelo apoio para freqüentar feiras no Brasil e no exterior.

A tabela 4 apresenta as respostas das empresas às questões que embasaram a abordagem acima.

Tabela 4 - PERCEPÇÃO DAS EMPRESAS SOBRE A IMPORTÂNCIA DE ASPECTOS LIGADOS À BASE INSTITUCIONAL

\begin{tabular}{l|c|c|c|c}
\hline \multicolumn{1}{c|}{ Aspectos observados } & $\begin{array}{c}\text { Positivo para a } \\
\text { competitividade }\end{array}$ & $\begin{array}{c}\text { Negativo para a } \\
\text { competitividade }\end{array}$ & $\begin{array}{c}\text { Sem influênc. na } \\
\text { competitividade }\end{array}$ & $\begin{array}{c}\text { Total de } \\
\text { empresas }\end{array}$ \\
\hline Meios de formação profissional & 15 & 2 & 5 & 22 \\
\hline Desempenho da administração municipal & 1 & 6 & 10 & $17\left(^{*}\right)$ \\
\hline Participação em associações empresariais & 13 & 0 & 9 & 22 \\
\hline
\end{tabular}

FONTE: Pesquisa direta nas empresas.

(*) Cinco empresas não quiseram se manifestar sobre a administração municipal.

\section{O problema da cooperação}

$\mathrm{Na}$ percepção de boa parte das empresas pesquisadas, a cooperação não se encontra ausente da realidade têxtil-vestuarista do Médio Vale do Itajaí (conforme a tabela 5, mais adiante). Entretanto, é preciso relativizar tal entendimento, pois a cooperação detectada nas entrevistas dizia respeito, principalmente, às relações de boa vizinhança entre algumas firmas. Em quase todos os casos puderam ser captadas manifestações de simpatia por ações em nível local capazes de gerar ganhos coletivos. Contudo, foram numerosas as indicações de que o excesso de individualismo e o espírito de rivalidade e desconfiança dos fabricantes configuravam obstáculos consideráveis. Tal quadro caracterizou notadamente a situação de Blumenau: várias empresas informaram que protagonizam empréstimos de materiais e máquinas em momentos de dificuldades para outras firmas, participam de 
reuniões com relativa freqüência (sem que, no entanto, assuntos relacionados aos negócios figurem no centro das atenções, de acordo com as entrevistas) e até interagem razoavelmente, sobretudo os fabricantes mais tradicionais, mas nunca se deixou de assinalar os problemas derivados de um individualismo intenso e de um estilo de concorrência que não raramente se revela desleal.

Em Brusque, as indicações de que há empréstimos de materiais, encontros freqüentes com concorrentes e outras demonstrações de colaboração e solidariedade apareceram acompanhadas de referências a iniciativas de ação conjunta de relativo alcance. Por exemplo, assinalou-se que empresas de tecelagem e prestação de serviços de beneficiamento (tinturaria, sobretudo) acertavam coletivamente níveis de preços, visando a definir padrão de comportamento no mercado. De outra parte, na primeira metade dos anos 90 funcionara uma associação de fabricantes de felpudos na qual se discutiam problemas de interesse do segmento e se definiam patamares de preços. Mas também em Brusque foram detectados problemas. A mencionada associação de fabricantes encerrou as atividades em 1995 devido a discordâncias que acabaram por se revelar insanáveis. Uma firma de artigos de vestuário, especializada em lingerie, informou agir com bastante cautela em matéria de interação com outros fabricantes desde que teve modelos para novos lançamentos copiados por concorrente, que obteve as informações através do representante que fornecia insumos para ambos. Contudo, tais episódios parecem mais exceções em trajetória que registra algumas importantes iniciativas de ação conjunta, mais intensas e conseqüentes do que em alguns outros locais do estado, entre eles Blumenau.

Em Blumenau, de fato, aludiu-se a várias tentativas frustradas de cooperação interfirma. Um fabricante de travesseiros procurara associar-se com outras empresas para comprar insumos no exterior, mas desconfianças recíprocas se interpuseram como obstáculo intransponível. Um outro fabricante de travesseiros e demais artigos da linha quarto, tradicional e de médio porte, reconheceu a importância da união entre empresas e assinalou o quanto se poderia avançar caso fossem introduzidos mecanismos de colaboração que inclusive contemplassem a utilização comum de máquinas e equipamentos, mas deixou claro que algo assim nunca fora possível em virtude do grande individualismo e da rivalidade que sempre imperaram no seio do empresariado local. Outra empresa, média prestadora de serviços de estamparia e tingimento, estabeleceu acordo com firmas do mesmo segmento visando à operação em níveis de preços semelhantes, mas os parceiros simplesmente não cumpriram o combinado. Tais exemplos fornecem uma 
idéia sobre o quanto se está longe, no principal núcleo têxtil-vestuarista de Santa Catarina, de uma organização industrial sintonizada com o tipo de estrutura de relações que parece ganhar espaço em escala internacional.

Em Brusque, merecem realce os esforços protagonizados no âmbito de parcerias entre as empresas e a administração pública, objetivando fortalecer a condição (auto atribuída) de "Capital da Pronta Entrega", que envolveram sobretudo a instalação de centros comerciais. A proliferação dessas estruturas de vendas faz parte da trajetória da cidade como importante foco de comercialização de artigos têxteis e vestuaristas: iniciada nos anos 70, a movimentação ganhou intensidade nos 80 e, até 1994, representava a chegada diária de mais ou menos 60 ônibus repletos de compradores. Tentouse também articular o crescimento do comércio com o setor turístico, aproveitando o fato de Brusque estar localizada em região onde ocorrem as principais "festas de outubro" (festas típicas alemãs) de Santa Catarina, a mais famosa das quais é a Oktoberfest, de Blumenau: o município passou a realizar a Fenarreco (Festa Nacional do Marreco), em que se presta tributo às raízes germânicas de boa parte da população e geralmente logram-se resultados comerciais importantes na venda de produtos locais.

Cabe mencionar ainda a Feira Industrial de Brusque, realizada anualmente em período em que o litoral catarinense, principalmente Balneário Camboriú e as áreas próximas, recebe grande quantidade de turistas, muitos dos quais estrangeiros. ${ }^{11}$ É também exemplo de tentativa de promoção coletiva da indústria e do comércio local a campanha iniciada no segundo semestre de 1997 pela Comissão Executiva para o Desenvolvimento de Brusque (da qual fazem parte, além de organismos da administração municipal, a Associação Comercial e Industrial, a Câmara de Dirigentes Logistas, a Associação de Micro e Pequenas Empresas e os principais centros comerciais da cidade), com o objetivo de arrecadar recursos que permitissem uma ampla divulgação da cidade e viabilizassem cursos de profissionalização para o pessoal que atua no comércio.

Deve-se assinalar que as dificuldades para cooperação em Blumenau não significam que os empresários locais não se organizam para defender os seus interesses. Pelo contrário, sua capacidade de mobilização merece realce, a ponto de Giese (1991) ter considerado tratar-se de um "grupo estratégico" regional, isto é, formado por indivíduos ligados por interesses comuns. Também Tomio (1995, p. 220) não hesitou em assinalar que o grupo social em foco ostenta proximidade de interesses e alto nível de articulação

11 Blumenau também possui uma feira têxtil: trata-se da Expotêxtil, organizada anualmente desde meados da década de 90 . 
e, sobretudo, uma "predisposição estrutural à organização coletiva e à atuação concertada nos campos econômico, político-institucional e corporativo..."

Entretanto, a secular trajetória de Blumenau como área têxtilvestuarista engendrou notável diversificação no empresariado, que se revela estratificado entre o grande porte, onde ainda há forte identidade ligada à origem germânica dos colonizadores, o pequeno e médio porte, com número não desprezível de representantes, e o nível micro, composto de uma miríade de unidades; as três escalas conformam mosaico social em que não estão ausentes interesses conflitantes. A maior capacidade de organização, traduzida, entre outras coisas, em presença destacada e reiterada (ou pelo menos em considerável influência a este nível) em instituições de abrangência estadual, retrata a "flexão muscular" das grandes empresas tradicionais. As vinculações interfirmas que perduram, envolvendo concessões recíprocas que parecem lubrificadas por identidade étnica e afinidade cultural, como se observava nos primórdios da industrialização, estariam a implicar notadamente o subgrupo mais tradicional. O empresariado de menor expressão parece pouco apto à organização e mobilização coletivas, não obstante a existência de espaços de articulação como o representado pela ACIB.

\section{Itajaí}

\section{Luzes e sombras do cluster têxtil-vestuarista no médio Vale do}

O Médio Vale do Itajaí ostenta características de cluster industrial. Além da trajetória secular em termos setoriais (et pour cause), a região possui vários dos atributos das aglomerações geográfico-setoriais repertoriadas na literatura internacional: mercado de trabalho com incidência de habilidades especializadas, fornecedores (sobretudo de máquinas e equipamentos, até via representantes comerciais de empresas estrangeiras), prestação de serviços diversos e tecido institucional de relativa densidade, entre outras coisas. A área proporciona economias externas vinculadas às possibilidades de divisão do trabalho na produção (tendo em vista as amplas condições para subcontratação), de acesso a serviços e conhecimentos especializados e de utilização de atividades subsidiárias e conexas, entre outros aspectos. Inerentes aos processos de cluster, os "estoques de externalidades" revelamse fatores fundamentais para a competitividade das empresas e, desse modo, pode-se concluir que tiveram importância decisiva na trajetória do Médio Vale do Itajaí.

Entretanto, não se pode referir ao sistema local em termos de "distrito industrial". Os elementos acima referidos relacionam-se principalmente aos ganhos "passivos" associados aos processos de cluster. 
Como observado, a cooperação interfirma revela-se limitada na região. Cabe assinalar que existem diferentes modalidades de relações cooperativas entre empresas. Há vínculos verticais, que ocorrem tanto "para trás" (fornecedores, subcontratados) como "para a frente" (compradores, traders); vínculos horizontais, geralmente incluindo marketing conjunto de produtos, aquisições coletivas de insumos e utilização comum de instalações, máquinas e equipamentos especializados; e também vínculos multilaterais, envolvendo produtores locais (normalmente através de instituições com abrangência sobre o cluster como um todo) e que colocam lado a lado associações empresariais e a administração pública local, em colaboração de tipo públicoprivada. Essas diferentes relações, com os respectivos ganhos derivados da ação conjunta, são potencializadas pelos processos de cluster. Seus efeitos, assim como os das inerentes economias externas, podem ser estáticos, com repercussões somente em termos de eficiência, ou dinâmicos, manifestados em progresso técnico e tecnológico e em crescimento. Combinados representam promoção da competitividade, maior rapidez na inovação e melhoria das perspectivas de crescimento do sistema econômico localizado de que se trata.

A maioria das firmas entrevistadas no Médio Vale do Itajaí informou que as relações de cooperação locais envolvem especialmente manifestações de solidariedade na forma de empréstimos de materiais e disponibilização de capacidades produtivas em situações emergenciais. Os vínculos verticais, na maior parte, relacionam-se tão-somente à subcontratação de etapas dos processos produtivos (praticada por quase todas as empresas entrevistadas, como indica a tabela 5), já que as firmas se abastecem e vendem em diferentes mercados; as exportações, quando ocorrem, baseiam-se em iniciativas diretas das próprias firmas. Além disso, as relações de subcontratação são raramente impregnadas de sentido de colaboração estratégica: na maioria das vezes, trata-se de transferência de atividades marcada por interesse em reduzir custos e flexibilizar o uso de mão-de-obra, mediante relações geralmente caracterizadas por pressões e atritos.

O learning-by-interaction, apto a favorecer mais rapidez na aprendizagem e na inovação, sofre as restrições impostas por condutas de proteção de segredos até mesmo sobre questões relativamente corriqueiras. Como se realçou, as relações são prejudicadas por comportamentos marcados mais por rivalidade do que por inclinação à colaboração, em que, não raramente, afloram procedimentos nitidamente "predatórios" em detrimento das firmas menores. O individualismo dificulta até mesmo possibilidades de ações conjuntas como compras, utilização de equipamentos e acesso a informações, sem que o funcionamento de instituições de auto-ajuda, como 
associações empresariais, realmente contribua para pavimentar o caminho rumo a interações conseqüentes.

Tabela 5 - PERCEPÇÃO DAS EMPRESAS SOBRE A EXISTÊNCIA DE COOPERAÇÃO INTERFIRMA E SOBRE A OCORRÊNCIA DE SUBCONTRATAÇÃO

\begin{tabular}{|c|c|}
\hline Indicadores & $\mathrm{N}^{\circ}$ de empresas \\
\hline $\begin{array}{ll}\text { Sim } & \text { Presença de cooperação } \\
\text { Não } & \\
\end{array}$ & $\begin{array}{c}15 \\
7 \\
\end{array}$ \\
\hline $\begin{array}{ll}\text { Sim } & \text { Prática de subcontratação } \\
\text { Não } & \end{array}$ & $\begin{array}{c}19 \\
3\end{array}$ \\
\hline $\begin{array}{l}\quad \text { Atividades subcontratadas com maior freqüência } \\
\text { Costura total ou parcial } \\
\text { Tingimento } \\
\text { Corte } \\
\text { Estamparia } \\
\text { Bordado } \\
\text { Fiação }\end{array}$ & $\begin{array}{l}16 \\
4 \\
3 \\
3 \\
2 \\
2 \\
\end{array}$ \\
\hline
\end{tabular}

FONTE: Pesquisa direta nas empresas.

Todo o referido estaria a caracterizar especialmente Blumenau, pois em Brusque acredita-se ter percebido um nível de cooperação/ colaboração que há de ser mais elevado e abrangente. Pelo menos é o que sugerem as relações, visando a estimular as vendas, que frutificaram na criação de vários centros comerciais, inclusive com aproveitamento do surto de "turismo de compras" em passado recente. Para as empresas de menor porte, muitas vezes carentes de estruturas de comercialização sólidas, iniciativas do gênero normalmente afiguram-se essenciais.

Não é fácil indicar motivos para essa aparente maior mobilização coletiva em Brusque, vis-à-vis ao que se acredita ter percebido em Blumenau, separadas por cerca de $40 \mathrm{~km}$ e integrantes de um mesmo espaço de produção têxtil-vestuarista. É possível que as diversas interações, a articulação de interesses e a formulação de estratégias implicando distintos agentes enfrentem menos resistências na primeira do que na segunda devido à diferença de "tamanho" e do próprio grau de diversificação de ambos os sistemas produtivos locais. Sejam quais forem os motivos, o que se captou a respeito de Brusque sugere que nessa área há certos fatores que, conjugados, estariam a justificar algum otimismo quanto às possibilidades de desempenho em escala de aglomeração de fabricantes. 
De fato, Blumenau já apresenta considerável diversificação setorial e, apesar de desfrutar dos benefícios de uma "marca Blumenau", que representa espécie de selo de qualidade têxtil e praticamente garante aceitação generalizada dos produtos regionais, parece não ter abrigado iniciativas importantes com vistas à eficiência em âmbito coletivo. Entre os motivos pode estar o fato de as grandes empresas da área terem geralmente operado, pelo menos até recentemente, com elevado grau de verticalização. Assim, pode-se postular que numerosas vantagens potenciais incrustadas na localidade, todas tributárias da própria tradição setorial, tenham sido menos aproveitadas do que poderiam, o que deve ser deplorado principalmente perante as grandes dificuldades com que se defrontaram as atividades têxteis e vestuaristas nos anos 90 , especialmente no tocante às empresas de menor porte.

Realmente, com os desafios impostos pelas mudanças nas condições de concorrência, representando maiores exigências por inovações, aumento de qualidade, flexibilidade e segmentação na produção e agilidade no atendimento aos pedidos, é necessário avançar em relação ao aspecto "ativo" da eficiência coletiva. Isso implica que, às economias externas naturalmente proporcionadas pela situação de cluster, é preciso agregar a ação conjunta consciente, isto é, a efetiva cooperação interfirma. Todavia, há muito o que avançar nesse terreno no Médio Vale do Itajaí. Sequer a reconhecida herança sociocultural, vinculada à forte influência da imigração germânica, representou chance de quebra, ou pelo menos de enfraquecimento, do individualismo e do espírito de rivalidade entre os fabricantes.

\section{CONSIDERAÇÕES FINAIS}

A experiência internacional sugere que os clusters configuram ambientes favoráveis ao desenvolvimento industrial. Isso é verdade especialmente quando esses arranjos evidenciam atributos que autorizam a referência a "distritos industriais". Com efeito, os clusters representam a ocorrência de externalidades positivas, possibilitam acúmulo e concentração de competências tecnológicas e conhecimentos ligados à comercialização, e estimulam - porém não garantem - o funcionamento das firmas em redes de cooperação onde capacidades produtivas com especializações complementares podem ser encontradas.

Tudo isso é importante sobretudo para as PMEs, que "podem ser competitivas caso recuperem como aglomeração as vantagens coletivas de 
que carecem individualmente em virtude de seu tamanho reduzido" (BIANCHI; TOMMASO, 1998, p. 620). Não admira, portanto, que, na atualidade, em diferentes países, o problema das relações interfirmas e institucionais em nível de cluster se constitua no principal foco das políticas de promoção de PMEs. ${ }^{12}$ Trata-se, geralmente, nessas políticas, de fortalecer a especialização e a complementaridade, o que envolve construir ou consolidar ambientes férteis para a cooperação e a agregação dinâmica das firmas, com vistas ao aumento da inovação e da eficiência. Para tanto, é necessário muito mais do que a instalação de infra-estrutura: galvanizar laços baseados na confiança, de modo a estimular a cooperação, constitui providência essencial.

Conforme salientado neste trabalho, o Médio Vale do Itajaí configura um autêntico cluster têxtil-vestuarista no Brasil meridional, sedimentado no curso de trajetória mais do que secular. Todavia, enquanto coletividade de fabricantes, a região ostenta carências principalmente em relação à natureza e abrangência dos vínculos cooperativos entre firmas, o que torna difícil utilizar a noção de "distrito industrial" para aludir à área.

Assim, em sintonia com a idéia segundo a qual as empresas conseguem identificar as oportunidades incrustadas na globalização especialmente ao longo de processos de aprendizagem coletiva, estratégias de fortalecimento do Médio Vale do Itajaí enquanto cluster têxtil-vestuarista, na perspectiva de uma possível trajetória rumo à condição de "distrito industrial", deveriam contemplar a promoção de entorno apropriado ao desenvolvimento de vínculos interfirmas densos. Naturalmente, as iniciativas de política em nível local devem almejar resultados amplos. Lograr melhoria nos serviços de apoio à produção e comercialização, ganhos de escala baseados em efetiva divisão do trabalho entre firmas especializadas e complementares e também aumento de qualidade e produtividade na subcontratação constitui meta importante. Mas é necessário situar no centro das preocupações o problema do aprofundamento das interações interfirmas, abrangendo questões como, por exemplo, o acesso coletivo a serviços e as aquisições conjuntas de insumos e matérias-primas.

O clima de rivalidade e individualismo que prevalece entre os empresários da região indica que alterar o quadro de precária cooperação vigente requer mudanças de mentalidade e revisão de posturas arraigadas, com enraizamento da idéia de que iniciativas conjuntas, implicando coletivos de agentes, configuram procedimentos que podem auxiliar uma travessia mais tranqüila dos períodos de turbulência. Os anos 90 representaram contexto

12 Consultar Bianchi (1997) sobre o assunto. 
dessa natureza: como outras regiões industriais do Brasil, o Médio Vale do Itajaí foi profundamente afetado pelas mudanças nas condições de concorrência protagonizadas no país, enfeixadas principalmente em abertura comercial que produziu avalanche de artigos importados nos mercados internos e representou consideráveis pressões por reestruturação produtiva e organizacional. Por si só, as conseqüências dessas mudanças indicam a necessidade de políticas de apoio, principalmente dirigidas às empresas, principalmente às PMEs, e a pedra angular de tais políticas há de ser o problema da cooperação.

É fundamental que se explicite junto aos agentes instalados no Médio Vale do Itajaí o sentido de pertencer a uma coletividade, incutindo a visão de que somente no plano coletivo é possível enfrentar os novos desafios. Isso é tarefa para instituições públicas, principalmente, ainda que em parceria com a esfera privada.

\section{RESUMO}

Este trabalho focaliza a questão dos clusters industriais, presente em alguns estudos atuais de economia industrial e desenvolvimento regional. Seu objeto é o cluster de produção têxtil-vestuarista do Médio Vale do Itajaí, em Santa Catarina, e sua base empírica compreende os resultados de entrevistas em instituições e em 22 empresas, na maioria pequenas e médias, instaladas em Blumenau e Brusque, as principais cidades da região. Na primeira parte do texto discorre-se sobre a problemática geral dos clusters industriais. Em seguida, identifica-se o cluster têxtil-vestuarista do Médio Vale do Itajaí. Depois, abordam-se aspectos locais relacionados às características da mão-de-obra, à herança sociocultural, às instituições e ao problema da cooperação entre agentes. Ao final, propugnam-se medidas de promoção que contemplem a superação da rivalidade e do individualismo entre os atores e que estimulem a cooperação, de modo a melhorar as condições de travessia dos períodos de adversidades.

Palavras-chave: clusters industriais, produção têxtil-vestuarista, Médio Vale do Itajaí, cooperação. 


\begin{abstract}
This article is about industrial clusters, a question frequently considered in some present studies of industrial economics and of regional development. Its subject is the cluster of textile and garment production of the Medium Itajaí Valley, in Santa Catarina, and its empirical basis are the results of interviews in institutions and in 22 enterprises, mostly of small and medium size, operating in Blumenau and Brusque, the region's main cities. The article looks firstly at industrial clusters in broad terms. Secondly, it describes the textile and garment production cluster of the Medium Itajaí Valley. Thirdly, it approaches some local features concerning work force, social and cultural background, institutions and the problem of cooperation among agents. In the concluding section, it argues that measures of promotion contemplating the reduction of rivalry and individualism and the improvement of cooperation are necessary, if local conditions to face adverse circumstances are to be ameliorated.

Key-words: industrial clusters, textile and garment production, Medium Itajaí Valley, cooperation.
\end{abstract}

\title{
REFERÊNCIAS
}

BECCATINI, G. Le district marshallien: une notion socio-économique. In: BENKO, G.; LIPIETZ, A. (Dirs.). Les régions qui gagnent. Paris: Presses Universitaires de France, 1992a. p. 35-55.

BECCATINI, G. Le district industriel: milieu créatif. Espaces et Sociétés, n. 66-67, p. 147-163, 1992 b.

BIANCHI, P. Industrial policy initiatives in support of small and medium-scale industry: impact of changes in industrial structure and integration on SMI clusters. In: SEMINAR ON NEW TRENDS AND CHALLENGES IN INDUSTRIAL POLICY, UNITED NATIONS INDUSTRIAL DEVELOPMENT ORGANIZATION, 1997, Vienna. Abstracts...Vienna: [s. n.], 16-17 October 1997. Mimeog.

BIANCHI, P.; TOMMASO, M. R. di. Política industrial para las Pyme en la economía global. Comercio Exterior, v. 48, n. 8, p. 617-623, ago. 1998.

CUNHA, I. J. O salto da indústria catarinense: um exemplo para o Brasil. Florianópolis: Paralelo 27, 1992.

GIESE, B. A atuação política do empresariado catarinense dos ramos têxtil $e$ agroindustrial: demandas e canais de influência (1970-1985). Florianópolis, 1991. Dissertação (Mestrado em Sociologia Política) - Universidade Federal de Santa Catarina. HERING, M. L. R. Colonização e indústria no Vale do Itajaí: o modelo catarinense de desenvolvimento. Blumenau: Editora da FURB, 1987. 
MAMIGONIAN, A. Indústria. In: Atlas de Santa Catarina. Florianópolis: Gabinete de Planejamento e Coordenação Geral de Santa Catarina, 1986, p. 104-106.

MARSHALL, A. Principles of economics: an introductory volume. 8. ed. London: Macmillan, 1979.

NADVI, K. The cutting edge: collective efficiency and international competitiveness in Pakistan. Discussion Paper, Brighton, n. 360, July 1997.

NADVI, K.; SCHMITZ, H. SME responses to global challenges: case studies of private and public initiatives. In: SEMINAR ON NEW TRENDS AND CHALLENGES IN INDUSTRIAL POLICY, 1997, Viena. Paper... Viena: United Nations Industrial Development Organization, 16-17 Oct. 1997. Mimeog.

RABELLOTTI, R. Is there an "Industrial District Model"? Footwear districts in Italy and Mexico compared. World Development, v. 23, n. 1, 1995, p. 29-41.

RITAINE, E. La modernité localisée? Leçons italiennes sur le développement régional. Revue Française de Science Politique, [S. I.] v. 39, n. 2, p. 154-177, avr. 1989.

SANTA CATARINA EM DADOS. Florianópolis: Federação das Indústrias do Estado de Santa Catarina. Setor Econômico-Estatístico, 1996. v. 7.

SCHMITZ, H. On the clustering of small firms. IDS Bulletin, Brighton, University of Sussex, v. 23, n. 3, p. 64-69, July 1992.

SCHMITZ, H. Collective effiency: growth path for small-scale industry. The Journal of Development Studies, v. 31, n. 4, p. 529-566, Apr. 1995a.

SCHMITZ, H. Small shoemakers and fordist giants: tale of a supercluster. World Development, v. 23, n. 1, p. 9-28, 1995 b.

SCHMITZ, H. Collective efficiency and increasing returns. IDS WORKING PAPER, Brighton, n. 50, Mar. 1997.

SCHMITZ, H. MUSYCK, B. Industrial districts in Europe: policy lessons for developing countries? World Development, v. 22, n. 6, p. 889-910, 1994.

SINGER, P. Desenvolvimento econômico e evolução urbana: análise da evolução econômica de São Paulo, Blumenau, Porto Alegre, Belo Horizonte e Recife. 2. ed. São Paulo: Editora Nacional, 1977.

TOMIO, F. R. de L. Organização coletiva e representação de interesses do empresariado industrial têxtil de Blumenau - SC: a atuação da ACIB e do SINTEX em um espaço político-institucional democrático (1985-1994). Florianópolis, Dissertação (Mestrado em Sociologia Política) - Universidade Federal de Santa Catarina. 